\title{
Kajian Eksperimen Perbandingan Nilai Konduktivitas Bahan Kuningan, Baja Tahan Karat, dan Aluminium Menggunakan PASCO Heat Conduction Apparatus TD-8513
}

\author{
Verna A. Suotha ${ }^{*}$, Hesky S. Kolibua, Handy I.R. Mosey a, Tiffany M.J. Kulona \\ aJurusan Fisika, FMIPA, Unsrat, Manado
}

KATA K U N C I

Konduktvitas Panas

Kuningan

Besi Tahan Karat

Aluminium

\begin{abstract}
A B S T R A K
Konduktivitas panas adalah salah satu karakteristik suatu bahan yang menunjukkan nilai aliran panas yang mengalir dalam satu luasan. Dalam studi eksperimental ini, nilai konduktivitas diuji dan di bandingkan dengan menggunakan Peralatan Konduksi Panas PASCO TD-8573. Peralatan ini memiliki 4 bar metal : satu Almunium, satu Baja tahan karat, dan dua Kuningan dengan potongan lintas yang berbeda. Salah satu bagian ujung dari tiap bar di panaskan atau didinginkan dengan alat peltier. Tiap bar memiliki 10 kilo ohm termistor yang tertancap $3 \mathrm{~cm}$ satu sama lain. Tujuan dari studi ini adalah untuk mengukur konduktivitas panas dari Kuningan, Baja tahan karat, dan Almunium. Hasilnya, konduktivitas Almunium adalah yang terbesar diikuti oleh Kuningan, dan yang terakhir Baja tahan karat
\end{abstract}

\section{A B S T R A C T}

Heat conductivity is one of the characteristics of a material which shows the amount of heat flowing across one unit of area. In this experimental study, the conductivity values are tested and compared using PASCO Heat Conduction Apparatus TD-8513. The apparatus has four metal bars: one aluminum, one stainless steel, and two brass with different cross-sections. One end of each bar is heated or cooled by a Peltier device. Each bar has two $10 \mathrm{k} \Omega$ thermistors embedded about $3 \mathrm{~cm}$ from each other. The purpose of this study was to measure the heat conductivity of Brass, Stainless steel, and Aluminum. The results, the conductivity of Aluminum was biggest were followed with Brass were and finally the Stainless steel

\begin{tabular}{l}
\hline TERSEDIA ONLINE \\
\hline 01 Agustus 2019 \\
\hline
\end{tabular}

1. Pendahuluan

Proses perpindahan panas secara konduksi adalah suatu proses perpindahan energi panas dimana energi panas tersebut mengalir dari daerah yang bersuhu lebih tinggi ke daerah yang bersuhu lebih rendah dalam suatu medium padat atau fluida yang diam. Persamaan umum laju konduksi untuk perpindahan panas dengan cara konduksi dikenal dengan hukum Fourier (Fourier's law) yang dipersamaankan seperti dibawah :

$$
q_{\text {cond }}=k A \frac{T_{1}-T_{2}}{\Delta x}=-k A \frac{\Delta T}{\Delta x}
$$

\footnotetext{
Dengan :

$q_{k} \quad=$ Laju perpindahan panas konduksi (Watt)

$k=$ Konduktivitas termal bahan $(\mathrm{W} / \mathrm{m} . \mathrm{K})$

A $=$ Luas penampang tegak lurus terhadap arah aliran panas $\left(\mathrm{m}^{2}\right)$

$\Delta T / \Delta x=$ Gradien suhu (perubahan temperature terhadap arah $\mathrm{x})(\mathrm{K} / \mathrm{m})$
}

\footnotetext{
*Corresponding author: Jurusan Fisika FMIPA UNSRAT, Jl. Kampus Unsrat, Manado, Indonesia 95115; Email address: vernasuoth@unsrat.ac.id Published by FMIPA UNSRAT (2019)
} 


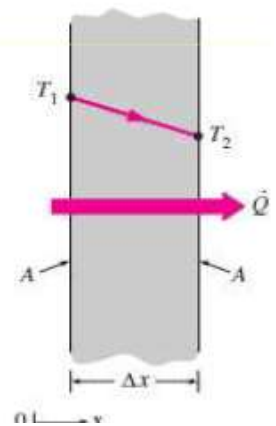

Gambar 1. Perpindahan panas secara konduksi

Tanda negatif (-) diselipkan dalam hukum Fourier yang menyatakan bahwa panas berpindah dari media bertemperatur tinggi ke media yang bertemperatur lebih rendah dan laju perpindahan panas konduksi pada suatu plat juga sebanding dengan beda temperatur diantara dua sisi plat dan luas perpindahan panas tetapi berbanding terbalik dengan tebal plat [1]. Kuningan adalah logam campuran dari tembaga dan seng. Kuningan kebanyakan digunakan untuk membuat pipa,tabung, sekrup, radiator, alat musik, aplikasi kapal laut, dan casing cartridge untuk senjata api [2]. Aluminium adalah salah satu golongan III A yang merupakan unsur logam yang berwarna putih perak mengkilat. Logam ini tahan korosi dan tidak beracun maka digunakan untuk alat rumah tangga seperti: panci, dan wajan [3]. Baja tahan karat merupakan paduan dari beberapa logam dengan komposisi tertentu. Bahan ini memiliki kandungan chromium minimal 10,5\%. Biasanya digunakan untuk arsitektur, seperti atap, talang pintu, jendela, dan tangki kimia [4].

\section{Material dan Metode}

Teknis pengukuran dilakukan dengan menggunakan PASCO Heat Conduction Apparatuss TD-8513 sebagai alat utama pemanas dan pendingin bahan uji logam. Alat ini dioperasikan dengan dihubungkan ke DC Power Supply, PASPORT Temperature Array PS-2157, dan PASCO GLX Explorer, lalu ke komputer.

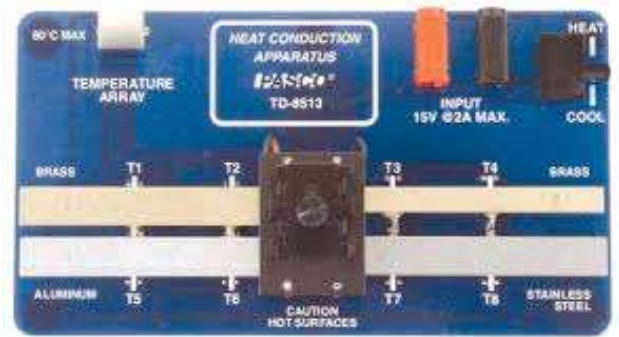

Gambar 2. PASCO Heat Conduction Apparatus TD8513

DC Power Supply berfungsi untuk mengatur dan menjaga tegangan yang masuk pada alat utama, PASPORT Temperature Array dan PASCO GLX Explorer berfungsi sebagai sensor pembaca suhu logam pada alat utama sekaligus mentransfer data hasil uji ke komputer.

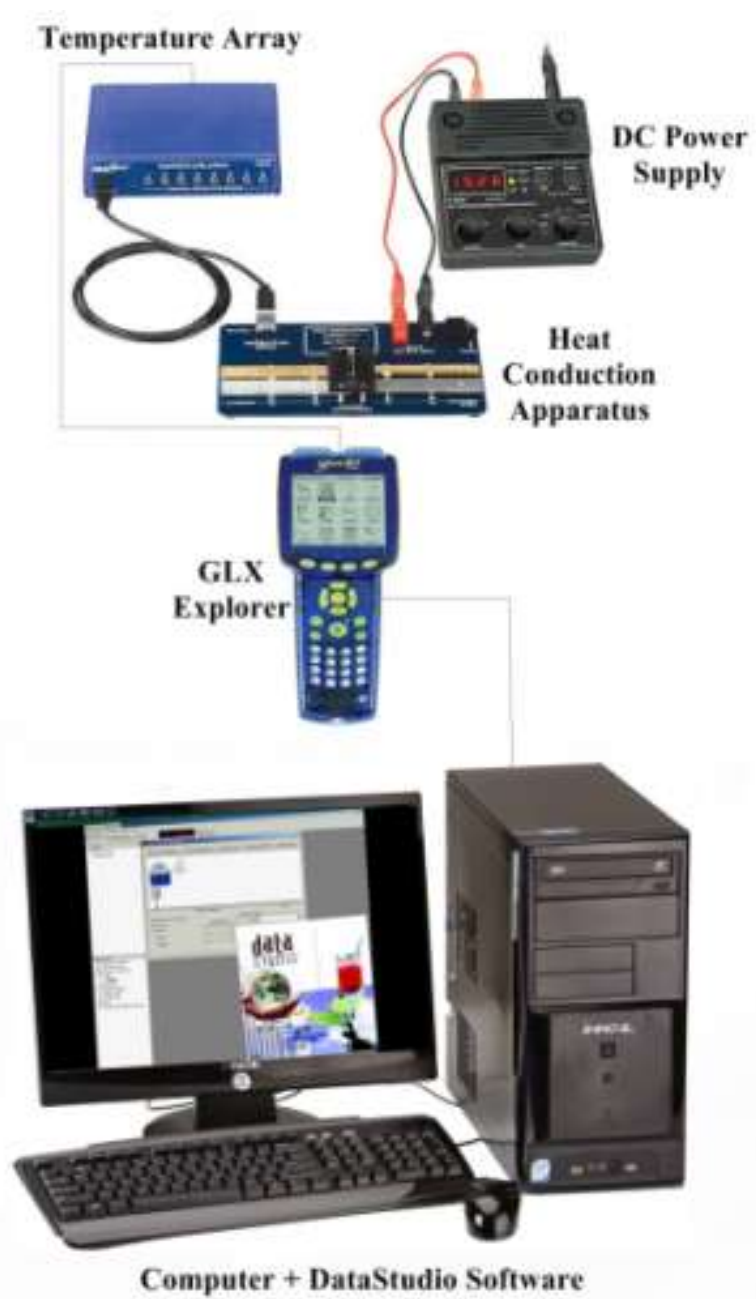

Gambar 3. Unit Fasilitas Pengujian

Software yang digunakan pada komputer untuk eksperimen ini adalah DataStudio. Dari DataStudio hasil pembacaan ditampilkan dalam bentuk grafik nilai suhu logam per satuan waktu. Pada tampilan grafik tersebut akan di lihat:

1. Suhu akhir dari tiap logam yang telah dipanasakan, logam mana yang memiliki konduktivitas yang paling tinggi dan yang paling rendah

2. Perbedaan laju konduktivitas pada kedua termistor "jauh" dan "dekat" logam.

3. Nilai perubahan suhu $(\Delta T)$ tiap bahan dan hubungannya dengan nilai konduktivitas

4. Perbedaan bentuk gelombang pada termistor "jauh" dan "dekat" pada logam.

5. Perbedaan kecepatan gelombang termistor "jauh" dan "dekat" pada logam,

Untuk nomor 1-3 Power Supply disetel ke $5 \mathrm{~V}$ DC Konstan. Dan dalam DataStudio laju pengukuran disetel menjadi $5 \mathrm{~Hz}$. Untuk nomor 4 ubah laju pengukuran di DataStudio menjadi $2 \mathrm{~Hz}$. Tombol HEAT dan COOL diubah bergantian secara manual setiap 30 detik. Untuk nomor 5 Power supply disetel ke output $8 \mathrm{~V}$ dengan Function Gelombang Segitiga positif, periode 50 detik otomatis, dan $2 \mathrm{~Hz}$ Laju 
pengukuran di Data Studio. Setelah semua telah disetel sesuai dengan prosedur, DataStudio dijalankan hingga kurang lebih 5 menit untuk melihat grafik hasil uji. Nama dari tiap grafik dilabelkan sesuai dengan nama label yang ada di Heat Conduction Apparatus:

T1 Wide Brass (far) T5 Aluminum (far) T2 Wide Brass (close) T6 Aluminum (close)

T3 Narrow Brass (close) T7 Stainless (close)

T4 Narrow Brass (far) T8 Stainless (far)

\section{Hasil dan Pembahasan}

Pada hasil peneitian tentang konduktivitas pana dari ketiga material adalah sebagai berikut:

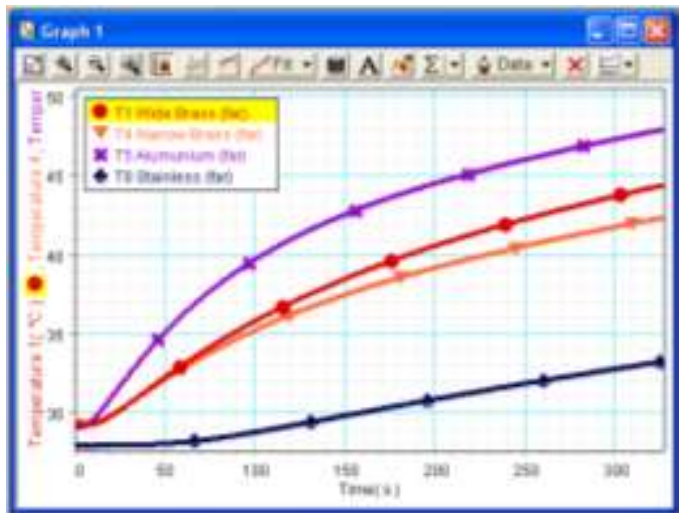

Gambar 4. Grafik suhu termistor "jauh"

Pada gambar 4 menunjukan suhu yang terukur oleh termistor "jauh" di tiap logam menunjukkan bahwa Almunium adalah konduktor terbaik dan Baja tahan karat adalah yang terburuk

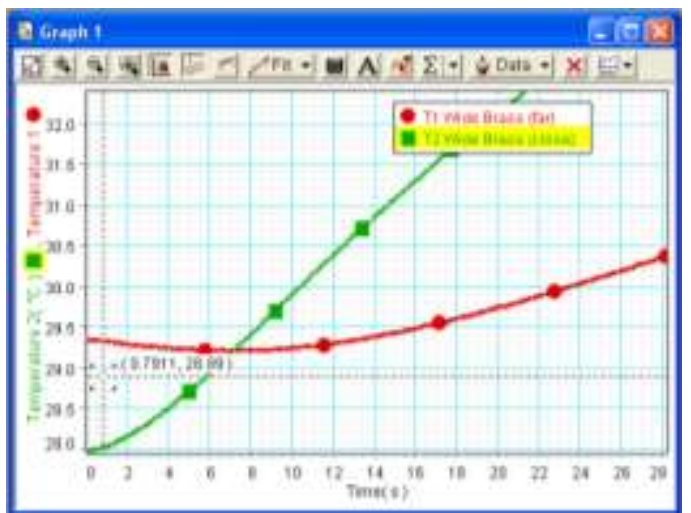

Gambar 5. Grafik laju konduktivitas dua termistor

Gambar 5 gelombang yang telah diperbesar pada dua termistor untuk logam kuningan menunjukkan getaran panas mulai muncul pada termistor "dekat" sekitar 9,9 detik sebelum termistor "jauh". Perbedaan jarak antara termistor adalah 30mm. Kecepatan getaran adalah $30 \mathrm{~mm} / 9,9$ detik $=3.03 \mathrm{~mm} /$ detik.

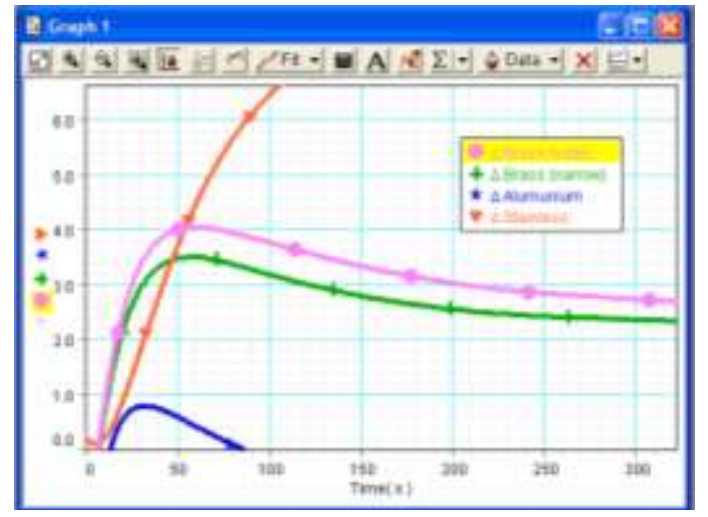

Gambar 6. Grafik $\Delta T$

Pada gambar 6 terdapat perbedaan suhu antara termistor di tiap logam yang menunjukkan bahwa Almunium (dengan $\Delta T$ terkecil) adalah konduktor terbaik dan Baja tahan karat (dengan $\Delta T$ terbesar) adalah yang terburuk. Untuk sampel data ini, nilai aliran panasnya adalah:

$\begin{array}{ll}\text { Kuningan lebar } & 0.36 \mathrm{~J} / \mathrm{det} \\ \text { Kuningan kecil } & 0.28 \mathrm{~J} / \mathrm{det} \\ \text { Almunium } & 0.28 \mathrm{~J} / \mathrm{det} \\ \text { Baja tahan karat } & 0.17 \mathrm{~J} / \mathrm{det}\end{array}$

Logam kuningan lebar memilki nilai aliran panas yang lebih tinggi daripada logam kuningan kecil. Hasil data juga menunjukkan bahwa nilai $\Delta T$ pada bahan yang berbeda tidak berhubungan langsung dengan nilai aliran panas.

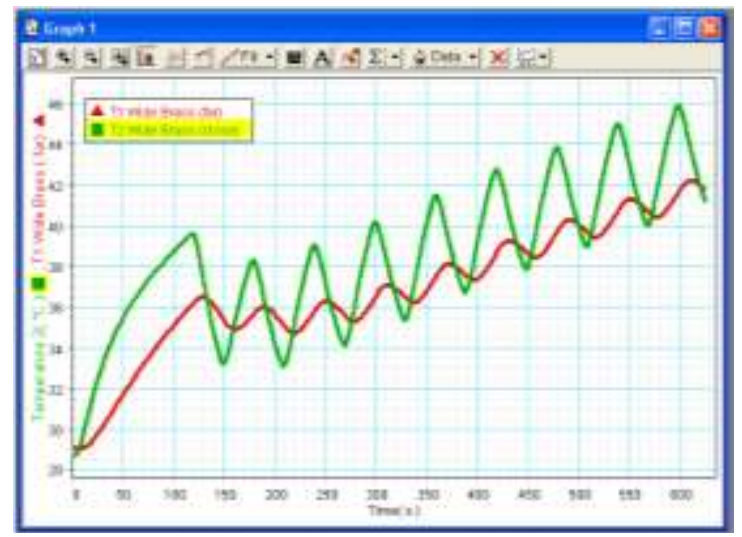

Gambar 7. Grafik bentuk gelombang dua termistor

Pada gambar 7 merupakan grafik bentuk gelombang dua termistor. Gambar ini menunjukkan suhu yang bertambah pada saat switich disetel ke posisi HOT (hingga mencapai $40^{\circ} \mathrm{C}$ ) dan mulai dipindah secara bergantian tiap 30 detik. Gelombang termistor "dekat" (bagian atas) gelombangnya menyerupai gelombang segitiga; pada termistor "jauh" gelombangnya lebih menyerupai gelombang sinus. Untuk data perbedaan bentuk gelombang dan kecepatan gelombang, yang diambil hanya dari eksperimen pada logam kuningan lebar termistor "jauh" dan "dekat".

T1 Wide Brass (far) 
T2Wide Brass (close)

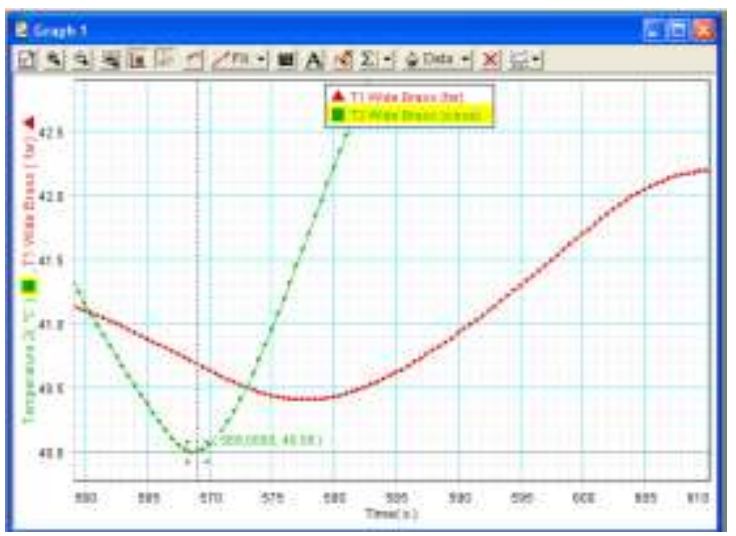

Gambar 8. Grafik kecepatan gelombang dua termistor periode 30 detik secara manual, Data Studio 2 Hz, Power Supply 5 V DC konstan.

Gelombang dari termistor "jauh" lebih lambat 9.5 detik dari termistor "dekat". Kecepatan gelombang adalah $30 \mathrm{~mm} / 9.5$ detik = 3.16 $\mathrm{mm} /$ detik

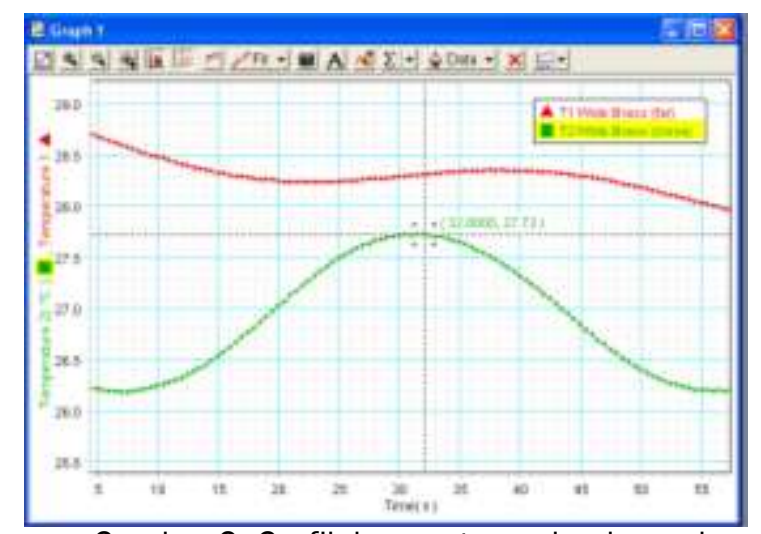

Gambar 9. Grafik kecepatan gelombang dua termistor periode 50 detik secara otomatis, Data Studio 2 Hz, Power Supply 8 V DC Gelombang Segitiga positif.

Pada grafik ini termistor "jauh" lebih lambat 12 detik dari termistor "dekat". Kecepatan gelombang adalah $30 \mathrm{~mm} / 12$ detik $=2.5 \mathrm{~mm} /$ detik Dari hasil pengamatan ini terlihat ada pelemahan amplitudo pada gelombang dibandingkan dengan ketika diberikan 5 V DC Konstan pada logam (pada Gambar 8). Dan kecepatan getaran dari 3.16 $\mathrm{mm}$ /detik menjadi $2.5 \mathrm{~mm} /$ detik. Termistor "dekat" memiliki kecepatan aliran konduksi yang lebih tinggi daripada termistor "jauh".

\section{Kesimpulan}

Dari hasil dan pembahasan dapat disimpulkan sebagai berikut :

1. Konduktivitas Almunium paling besar di bandingkan dengan Baja tahan karat dan Kuningan.

2. Konduktivitas Kuningan lebih kecil dibandingkan Almunium namun lebih besar bila dibandingkan dengan Baja tahan karat

3. Konduktivitas Baja tahan karat paling rendah dibandingkan Kuningan dan Aluminium.
4. Termistor "dekat" memiliki kecepatan aliran konduksi yang lebih tinggi daripada termistor "jauh".

5. Nilai $\Delta T$ pada bahan yang berbeda tidak berhubungan langsung dengan nilai aliran panas..

\section{Daftar Pustaka}

Frank P. Incropera and David P. DeWitt. Fundamentals of Heat Transfer, 4rd ed. John Wiley \& Sons, Inc., New York, 1996.

Afdhal Kurniawan Mainil. Kaji Eksperimental Alat Uji Konduktivitas Termal Bahan. Teknik Mesin, Universitas Bengkulu, 2012.

Petrucci, R. H. Kimia Dasar Prisnsip dan Terapan Modern Jilid 3. Jakarta: Erlangga, 1987.

http://www.aalco.co.uk/datasheets/StainlessSteel St-St-Introduction 61.ashx, diakses pada tanggal 01 April 2019, pukul 10:45 WITA. 